\title{
Love, a search for transcendence
}

\author{
Entretien avec Charles Lindholm ${ }^{1}$
}

\author{
Par Isabelle Jabiot, Maïté Maskens \\ et Carine Plancke
}

\section{Love and research history}

How did you come to work on love? How would you describe the way love appeared on your academic path and became part of your research?

When I was a graduate student at Columbia, one of my favorite professors, Robert Murphy, mentioned in passing that anthropologists wrote about violence, competition, and antagonism, but not about love. I filed his comment in my collection of his aphorisms, little imagining that I would ever be researching love myself.

So I was quite surprised when I found myself doing just that during my anthropological fieldwork with the Swat Pukhtun of Northern Pakistan - a famously aggressive society. What puzzled me was that, in stark contradiction to their prevailing ethos of competitive individualism, the Pukhtun had a strong value of unstinting hospitality, accompanied by an idealized non-sexual notion of male friendship, where each friend would instinctively sacrifice anything, including life itself, for the sake of the other. In my book Generosity and Jealousy², I mixed anthropology and psychology to conclude that "friendship and hospitality in Swat can best be understood as the expression, in a world of hostility and fear, of the necessary counterweight to the Pukhtun man's inevitable sense of isolation: love."(Lindholm 1982 : 273).

After finishing my ethnography and getting my first real job, I began working on another puzzle that once again made me think about love in its various forms. My question was: What is charisma? I first confronted this issue in the late 60s as some of my college classmates - apparently sane and normal - dropped out to devote themselves the worship of exotic gurus. My 1990 book Charisma combined Durkheim, We-

1 Professeur émérite d'Anthropologie, Boston University.

2 The work of Charles Lindholm could be find in Open Access here: http://open.bu.edu/browse?value=Lindholm\%2C+Charles\&type=author https://scholar.google.com/citations?user=zmQ3CPOAAAAJ\&hl=en. 
ber and Freud to argue that individuals enter groups gathered around inspiring leaders because they are in search of ecstatic states absent in daily life.

It was Durkheim who explained that "collective effervescence" occurs as a crowd coalesces around a totemic figure. Ecstatic self-loss in the crowd glues the group together in a moral community. But the triumph of individualism in the modern world meant that society was losing cohesion and in danger of being overwhelmed by alienation and anomie. However, as he wrote: "This state of incertitude and confused agitation cannot last forever. A day will come when our societies will know again those hours of creative effervescence." (Durkheim 1965 : 475).

Weber agreed that the "creative effervescence" of charisma occurred when a social order exhausted its moral authority. At that point the disenchanted masses became susceptible to the influence of a leader offering the immediate thrill of collective participation and (secondarily) a message of redemption. If charisma is to survive the death of the leader, the disciples must codify his spontaneous words and deeds into doctrine and ritual. Over time, the rationalized authority of the new order inevitably degenerates into rigid tradition. The time is then ripe for a new messenger to proclaim: "It is written, but I say unto you."

However, Weber argued that, with the advent of capitalism, charisma would henceforth exist only "pianissimo," arising harmlessly on the margins of society. In fact, the implacable forces of capital accumulation were not only crushing charisma, but also all types of idealization. As he wrote: "The routinized economic cosmos... has been a structure to which the absence of love is attached from the very root." (Weber 1946 : 355) In the cold new world of capitalism, the flame of collective effervescence that Durkheim promised was forever extinguished.

My contribution to this debate was to compare charisma in preliterate shamanic cultures to charismatic movements in the modern world. That comparison demonstrated that charismatic devotion was now more marginal, but also more intense, pathological, paranoid, and "world rejecting," than it was in earlier eras. Was Weber right? Could the upsurges of the present be interpreted as the paroxysms of a dying faith? Could capitalism stifle all other forms of human communion as well? Or, are there still avenues for achieving transcendence, as Durkheim hoped? Sporting events, church services, celebrity worship, the cult of the artist, do produce charisma, but these advents are scattered and peripheral, as Weber predicted.

It was clear to me that there remains another potent, common, and obvious alternative to charisma. This is romantic love, which offers individuals an equally gripping (and socially acceptable) emotional experience. I made this case in a paper (Lindholm 1988a). There I contended that charisma and romantic love are mutually exclusive and competing forms of a panhuman quest for escape from the prison of the self. Love now predominates over charisma in the modern struggle for human hearts. From this perspective, idealized romantic love is a universal possibility, but not a universal phenomenon. For example, it recedes when charisma prevails. It also follows that romantic love only flourishes under specific socio-cultural circumstances. 
Around the same time, I hired two of my brightest Harvard undergraduates (Andrew Buckser and Susan Rofman) to do blind readings of the ethnographic data in the Human Relations Area Files (HRAF). I asked them to look specifically at three files: "basis of marriage" (581), "suicide" (762), and "ideas about sex" (831). The "basis of marriage" file was an obvious choice, since cultures often link love and marriage, as is the case in the modern West. This correlation was generally taken for granted in the few cross-cultural studies of love that did exist. However, I knew that love does not always precede marriage. In fact, love and marriage may well be opposed, especially where marriage is an avenue for political alliance or economic benefit. To balance the love - marriage assumption, I asked my researchers to look for suicides that occurred as a reaction to rejection by the beloved, grief at a lover's death, or other obstacles to love. Suicides from hurt pride or shame or as revenge were excluded. The final category, "ideas about sex," yielded love stories and myths. At the same time, I kept in mind the lesson I had learned from the Pukhtun: idealization need not be sexual.

Together Andy and Sue compiled a final list of twenty-one societies where romantic love was strong. Due to the paucity of ethnographic data dealing specifically with romantic love, and the limitations of the HRAF, this number is an approximation at best. But it is significant that only a tenth of the sample had unequivocal evidence of romance, according to the standards we used for judgment (other surveys, using weaker criteria, found higher instances of romantic love).

Using this data base, with the addition of more complex social formations where some form of romantic love was evident (among others, Haien and Tokugawa Japan, imperial Rome, courtly society in Europe, tenth century India, ninth century Arabia, nomads in Iran, as well as love in the modern world), I hypothesized that there were at least three different "love complexes" that correlated with three distinct social formations (Lindholm 1998a). In the first, love is supposed to lead to marriage and the family. This pattern is characteristic of the modern West, and also of some hunting and gathering societies. Despite vast differences in complexity, these social formations are alike in that persons believe themselves to be autonomous agents, acting out of self-interest in the face of a hostile and unpredictable world. External authority is either non-existent or abstract and distant. In such fluid, individualistic, and threatening settings marriage between lovers provides both a haven and a heaven (shared by two) in a hostile world. Love also is expected to naturally rationalize over time and become "companionate" conjugal love.

Far more common cross-culturally is the complete rejection of any link between love and marriage. This pattern is characteristic of rigidly hierarchical social systems: caste societies, courtly orders, societies with hereditary chiefs, or segmentary lineages. In all of these, marriage is a power game played between rival groups of men: women are pawns in that game; love between husband and wife is ridiculous and impossible. Paradoxically, love relations in these societies regularly reverse patriarchal authority. Thus we find idolatry of courtesans in the French court, or Roman poets praising their beloved slave prostitutes as domina. Romantic idealization may even preclude sexual contact between the lovers, as in the fin amor of medieval court- 
ly love, or the chaste love glorified by (among others) the ancient Bedouin, the modern Marri Baluch nomads, and the Manus islanders, where, as Margaret Mead tells us, people say, "the wonderful thing about lovers is that you don't have to sleep with them." (Mead 1956: 405).

The fact that these types of love may coincide with a symbolic reversal of power and avoidance of sexuality may reflect the fact that in such societies romantic idealization, however deeply felt, can never be rationalized into a stable conjugal dyad. Because love is impossible to domesticate, it is likely to be fantastic and unrealistic in its imagery, more dangerous in its enactment (love suicides are common), more detached from sexuality. The impossibility of achieving marital stability intensifies a desire for communion that can only be satisfied by symbolic excesses and reversals. This is quite unlike societies of the first type, where romantic love becomes conjugal over time, just as institutionalization stabilizes a charismatic movement.

There is one other social formation that favors romantic love. It is found mostly in disharmonic societies in tribal India, Southeast Asia, and Oceania, where young people in age-graded clubhouses freely pursue sexual encounters, but only with partners whom they can never marry. Sometimes these sexual experiments evolve into intense romantic relationships. When the young lovers are faced with the inevitable fact of separation, they may commit suicide, joining together in death what is forbidden in life. Love suicides are commemorated in poems and songs praising the lost paradise of youth, where love was fleetingly possible.These shared memories and stories help to bind these fragile centrifugal social worlds together.

I then argued that romantic love - in any of its shapes - is unlikely to be important or even to exist at all in stable societies with solidified extended families, age-sets, or other encompassing social networks that offer alternative forms of personal transcendence through group rituals and other more mundane collective experiences. It followed that love could diminish and even disappear as a social formation changes. Some sociologists, notably Anthony Giddens (1992), believe this is exactly what is occurring in the modern Western world, as individuals find themselves afloat in a faceless and fluid neoliberal universe. In the new self-reflexive world, Giddens says that utilitarian "pure relationships" of negotiated pleasure will dominate.

I think Giddens is mistaken. Under the anomic conditions he describes idealized love may actually become even more salient as an escape from instrumentality and solipsism. But if he is correct, and romantic love does disappear, the utilitarian pure relationship he conjures up will necessarily be countered by some other expression of the human desire for self-transcendence: perhaps what will take its place is the collective worship of corporate bosses and technological innovators, or submission to demagogues.

In any case, I agree with Freud that under no circumstances can human beings be reduced to termites. We always seek to go beyond ourselves, and strive for the inspiring experience that is promised and sometimes realized in religion, mysticism, charisma, ecstatic trance, and love (for more complete statements of this argument, see Lindholm 1990, 1995, 1998b). 


\section{Love and research conditions}

You were amongst the first anthropologist to take the study of romantic love seriously. Do you think that the conditions and the environment for doing research in the human and social sciences have inhibited talk about love? Does the topic lack a certain legitimacy? If so, do you have some anecdote that could illustrate this?

Anthropologists need to be aware that approaching the emotionally powerful experience of love from an "external" social science perspective is likely to appear trivializing on the one hand, voyeuristic on the other. Also, until recently anthropology, as a marginalized discipline seeking approval from the mainstream, has favored the "masculine" science side over its "feminine" social side. Emotional subjective experiences such as love were irrelevant to, or at best subordinate to, the supposedly more important studies of power and class. This orientation has been challenged from many directions, but still retains some authority.

As a result of these two factors, those who venture into love's territory risk rejection, stereotyping, and even harassment. For example, one of my former students has written about the complex relationship between the Western discourse of love and the AIDS crisis in Africa. When she sent her articles to journals edited by men, they were sent to male area specialists to be reviewed (and rejected). One editor even said he would accept the paper if she would have a sexual relationship with him. Female editors were far more sympathetic to her work, and sent her papers to be reviewed (and accepted) by female gender specialists. This gender bias suggests that studies of love can be published, but are at risk of being "feminized" and relegated to a specific "gender" niche. That isn't a bad thing per se, but if the study of love is to have a greater impact on the discipline, it will have to escape from stereotypes and reach a larger professional audience.

Do you think that love, just like everything else that deals with the emotional and intersubjective field, is considered to be subjective, irrational, feminine, etc. and that this makes talking about love a taboo or a sensitive issue?

As my answer above indicates, I agree with your premise. But I see signs that this negative attitude is changing. More and more innovative works on emotion, intersubjectivity, the irrational in general and love in particular, are being written by both male and female anthropologists. It is worth keeping in mind as well that taboo topics are liminal. For those who dare to cross the threshold, new perspectives reveal themselves.

Do scholars observe that they are somehow obliged to legitimate their choice while this obligation does not exist for other research topics? 
Personally, I have never found this to be the case. But I have been very lucky to work in cross-disciplinary environments and in creative Anthropology Departments where my own intellectual inclinations were accepted. I can well imagine that restrictions might be much tighter in other settings.

How was your publication about love received? Did you receive very positive reactions or arguments of refutation?

After my first publications, I was invited to participate in some journal issues and book projects, which I enjoyed. Even now, I am sometimes asked to contribute encyclopedia entrees on love (I just submitted one). Your invitation to write this interview testifies that I still have some remaining aura. However, my cross-cultural and historical approach to the study of romantic love, and my hypothesis that love is only one form of an existential hunger for a felt connection with the "more" mentioned by William James, has not gained much traction with my fellow scholars. The evolutionary approach that makes love into a biological compulsion seems to be more appealing. This is a little disappointing, but I continue to hope that my approach might eventually have more influence. Mostly, I am pleased that the subject of love - which was so little discussed when I began my work - has grown and become much more sophisticated. Even the socio-biologists, whom I once dismissed completely, and who returned the favor, have been giving serious attention to cultural factors in their analyses. I like to think some of that has been in response to my research.

You stated in 2006 that the lack of anthropological interest for studying love is a product of disciplinary anxieties about its own legitimacy: avoiding 'irrational' or 'subjective' issues in order to be recognised as an objective science of culture. Do you think the situation has changed during this last decade? Do you think the investigator of love today is no longer an "absurd figure"?

In general, laymen as well as social scientists in Western culture do tend to find anthropologists exotic, useless, and somewhat silly. Who cares about the people we work with? Who can understand the jargon we use to talk about them? Those who study love and other intimate topics are even easier to portray as absurd and prurient snoops than those who study practical subjects. At least the latter might tell us something "useful." Yet, I have found that my courses on love resonate strongly with students and that my writings interest colleagues in other disciplines perhaps more than they interest fellow anthropologists. It is possible that new writing on emotion, subjectivity, and idealized relationships will help anthropology return into the mainstream that it abandoned after the collapse of the Culture and Personality school popularized by Margaret Mead and Ruth Benedict. Certainly the material casts light on very fundamental aspects of human experience. That should interest everyone.

\section{Love, structure and utopia}


You reject functionalist, cynical or materialistic analysis of romantic love which try to "unmask" the real intentions or motivations for romantic love (as a commodified illusion, a discourse of the sexual predator, a direct response to capitalism, an evolutionary mechanism...etc.) because it does not do justice to the experience and narratives of the lovers. You propose a definition of romantic love as a form of the sacred, an experience of transcending the existential limits of the self and a creative act of human imagination. In a sense, you are saving romantic love from its postmodern disgrace. Do you agree with the idea that there is an almost a religious tone is this definition, an idea of the good, a utopia, a form of hope?

You state my position better than I can. Perhaps another way to put it is that religion (at least in the West) partakes of the tone of romantic love, which could, with some justice, be seen as the saving grace in a culture of possessive individualism.

According to you, why is ethnography so important in the study of love?

Ethnography is important for the study of anything and everything. But it is more important for love because love is felt to be so personal, unique, and unquantifiable. Interviews, surveys, and literature reviews provide important material, of course. But one can never get the spontaneous expressions and anecdotes that provide real insight into an emotional relationship without "being there."

You develop a structural and comparative study of romantic love in order to outline the circumstances and trajectories of love in various cultures. Do you think the next generation of anthropologists still have a lot of work to do to obtain a well-documented global view of the phenomenon?

Yes, there is plenty to do. Clearly, the conquest of the world by capitalism is proceeding apace, eradicating or at least sublimating alternative forms of emotional experience. As a result, the "love leads to marriage" paradigm is rapidly becoming the global default mode for romantic relationships, and as a disguise for sexual desire. However, earlier forms of idealization and of sexuality persist beneath the surface and in alternative spaces, where they can still be traced. Doing so before they disappear or are completely altered is an urgent task for anthropological research. Equally pressing is discerning and analyzing the structures that arise in the dialectic between modern romantic idealization and alternative indigenous routes to self-transcendence. Finally, I think anthropologists should make consistent and careful comparisons between romantic love and other idealized relationships (charisma, friendship, hero worship, celebrity culture, and so on). In this way we might make progress on a cross-cultural theory of human impulses toward submission and worship. If followed, these agendas should occupy anthropologists for a very long time to come.

\section{The impact of love on fieldwork and on anthropology}


Do you think that to consider love as a serious matter in anthropology allows doing anthropology in a different way?

Perhaps. Though it wasn't the case for me. I did my own fieldwork in very traditional manner, living in a village and becoming a participant observer, absorbing and recording all that I could. I only thought about love when it offered a solution to a problem that arose in my analysis of my data. But researchers who begin with the idea of studying love will focus on love poems, love songs, love letters, local narratives about lovers, intimate revelations about love, careful observation of people who are in love (and those who aren't), et cetera. These data aren't necessarily much different, except in emphasis, from materials that ethnographers have used in the past. Perhaps the major distinction is that the study of love may require a closer attention to subtle emotional cues than is usually the case.

One type of data is, however, undeniably unique. That is material gathered from a love relationship between the anthropologist and the "informant." The question immediately arises: Can an ethnographer consciously be a participant and not just an observer of love? I would say no - especially where love is understood to be unplanned. But what if the ethnographer spontaneously falls in love with one of the people being studied? And what if the love is reciprocated? This is not unusual, and could be a valid source for comparative data of the most intimate kind, since culturally different attitudes toward love can then be explored from the "inside out." At the same time, the vast power, cultural, and status differences that usually exist between anthropologists and indigenes make exploitation a constant threat - and not only from the side of the anthropologist. For the local person, initiating a love relationship may be the best route out of a stultifying environment. This does not mean that love between an anthropologist and an informant must be totally compromised, but it does mean that such relations are very complicated. Writing about these relationships adds even more complication, as what is ideally private and emotional becomes a matter for public contemplation and analysis.

Do you think the debate about the importance of "mutuality" in ethnographic encounters is a way to address the question of love in our anthropological professional routines? We do not want to create the distorted image of the researcher who is always "passionate " about his or her research, but do you think that love for one's research, for the field or for the people encountered there is an important aspect of the professional life of an anthropologist

Forgive my ignorance, but I don't know much about the debate on mutuality in anthropological research. I'll try to answer anyway, working from the premise that anthropologists can say something about anything.

To begin, I've always assumed that we anthropologists must passionately love our work; otherwise why endure long and arduous training, the displacement, dangers, and diseases of fieldwork, and the high likelihood that no job will be waiting for us at 
the end of the road? One of the things that can offset all that travail is the romantic hope of living with, learning from, and becoming friends with strangers in a strange land. This hope was what drew me into anthropology in the first place. After college, I set off on my wanderjahren through South Asia. During my travels I made a good friend in a remote village in Northern Pakistan. After I got back to New York, I wanted to return to that village and that relationship. The study of anthropology allowed me to accomplish my goal.

While doing my fieldwork, I grew even closer to my friend and his family, but after I returned home, I did not go back to Pakistan. There were various reasons for this, the major one being that my interests turned toward more comparative and theoretical issues. The long distance relationship with my Pakistani friend did not survive the physical and cultural distance between us. It ended when I was unable (and unwilling) to bring him to the United States where he planned to spend every day with me and live in my tiny apartment. However, I do have a close friendship with one of his half brothers -an educated and cosmopolitan doctor who travels to the USA regularly and stays with his son. The moral is: what worked in the field may not work back home. Mutuality is conditional and contingent.

My situation and choices are not the norm for anthropologists, who mostly do go back to the field. I suppose that this is not just to gather new data, but also to reimmerse themselves in the fieldwork situation, where they can find again a semblance of the emotional tie that is such a precious gift to anthropologists. Sometimes the binding force of this tie can even lead to pulling away from earlier identities: this used to be called "going native." Less radically, anthropologists may become so emotionally entangled in the troubles and tribulations of "their tribe" that mutuality tips into identification, and they become spokespersons and activists, sometimes sacrificing career opportunities for the sake of their oppressed friends.

The reverse of identification with the other can also happen: some anthropologists I know have had difficult times in the field as a result of mistaken expectations, leading to resentment, misunderstanding, and feelings of exploitation on both sides. Or the cultural style of a particular setting may simply be aesthetically and psychologically unappealing. One of my colleagues admired the nomads he knew and was happy to live with them; in contrast, he found peasants irritating, grasping, and dull. He avoided them. Other anthropologists discover that changing political settings in their research site can lead to permanent estrangement from old friends. Or they may find that violence and poverty in the field site are too hard to stomach, and that cultural differences are too vast to permit mutual recognition. Again: mutuality is conditional and contingent.

But when mutuality does occur, the bond established between the researcher and the informant in some ways does resemble a love affair, in that it is a collaborative exchange based on reciprocal trust and regard. And, in certain circumstances, it can also be an idealized relationship, from both sides. Yet this relationship must always contain complicating elements of exploitation and dependency, as I discussed in my last answer, where I considered love affairs between ethnographers and locals. 


\section{Effects of the knowledge of love on the experience of love}

In a more general way, does learning or researching "on" love influence the way of "experiencing", "doing" and "performing" love in daily life? How? Has your work on this topic impacted on your personal life, on your way of being "in love"?

I don't think studying love has had any impact on my own experience of love. Reading and writing about love, developing critical conceptual frames to understand love, even researching love as an anthropologist, is an intellectual exercise. Love itself is outside or beyond all that. It can't be coerced, but impels, like a flood. Not to say that love is always a coup: It can well up slowly, gradually eroding resistance, until the boundaries between self and other are blurred and even erased. Being conscious of the process makes no more difference than if a photographic plate were conscious of being imprinted.

Of course, love is also stereotyped. We know how it is supposed to be performed, and try to follow the standard script. But there is a big difference between playing a role and living the role. As the song says: "Life is a game. We play different parts. But if you want my love, you've got to play it with your heart." In this fundamental sense, love is very like religion, as described by William James (1982) - an experience, not a doctrine.

As for me, I am a believer.

\section{Bibliographie}

Durkheim E. (1965), The Elementary Forms of Religious Life, New York, The Free Press.

GIDDENS A. (1992), The Transformation of Intimacy: Sexuality, Love and Intimacy in Modern Societies, Stanford, University of California Press.

JAMES W. (1982), The Varieties of Religious Experience, New York, Viking Penguin.

Lindholm C. (1982), Generosity and Jealousy: The Swat Pukhtun of Northern Pakistan, New York, Columbia University Press.

Lindholm C. (1988), «Lovers and Leaders: A Comparison of Social and Psychological Models of Romance and Charisma », Social Science Information, vol. 27, p. 3-45

LindHolm C. (1990), Charisma, Oxford, Basil Blackwell.

LindHolm C. (1995), «Love as an Experience of Transcendence», In W. JANKowiak (ed.) Romantic Passion: A Universal Experience?, New York, Columbia University Press.

Lindholm C. (1998a), «Love and Structure », Theory, Culture, and Society, vol. 15, p. 24363. 
Lindholm C. (1998b), "The Future of Love», In V. DE MuncK (ed.) Romantic Love and Sexual Behavior: Perspectives from the Social Sciences, Westport, Praeger.

Lindholm C. (2006), « Romantic Love and Anthropology », Etnofoor, vol. 10, p. 1-12.

Mead M. (1956), New Lives for Old; Cultural Transformation - Manus, 1920-1953, New York, Morrow.

Weber M. (1946), "Religious Rejections of the World and Their Directions ", In H. GerTH and C. W. Mills (eds.) From Max Weber: Essays in Sociology, New York, Oxford University Press. 